\title{
A formação do professor e o processo de ensino-aprendizagem da língua portuguesa para alunos surdos
}

\author{
Angela Corrêa Ferreira Baalbaki \\ Universidade do Estado do Rio de Janeiro (UERJ)
}

\begin{abstract}
Resumo
O presente artigo tem como objetivo apresentar as especificidades de uma disciplina oferecida em curso de graduação em Letras. Em consequência da atual política educacional inclusiva, especialmente, em relação aos alunos surdos, configurou-se, em âmbito acadêmico, um espaço profícuo de debates acerca de métodos, estratégias e abordagens endereçadas às necessidades linguísticas desse grupo discente em relação ao ensino de Língua Portuguesa (LP). Acrescenta-se a este panorama demandas relacionadas à produção e à adequação de materiais que estabeleçam a transposição didática de conteúdos relacionados à modalidade escrita da LP. Palavras-chave: ensino de português para surdos; elaboração de materiais; prática acadêmica
\end{abstract}

\begin{abstract}
This article presents the specificities of a discipline taught in an undergraduate course in Letters. As a result of the current education policy on inclusion, especially in relation to deaf students, there have arisen productive debates about methods, strategies, and approaches in the academic sphere oriented to the language needs of this student group, particularly their linguistic needs regarding the teaching of the Portuguese Language. In addition, there are questions concerning the production and suitability of materials that can provide a didactic transfer of contents for the written mode of Portuguese.
\end{abstract}

Key words: teaching portuguese to deaf students; materials development; academic practice

\section{INTRODUÇÃO}

O processo educacional da comunidade surda, no Brasil, passou por várias etapas que, em geral, desprestigiavam sua primeira língua, a Língua Brasileira de Sinais (LIBRAS). Após a promulgação da Lei n ${ }^{\circ} 10.436$, de 24 de abril de 2002, que reconhece a LIBRAS como meio de expressão e de comunicação da comunidade surda e de instrução de conteúdos escolares, observa-se a introdução de uma política de 
educação bilíngue. No entanto, na educação de surdos, vários problemas ainda não foram devidamente solucionados.

Segundo Fernandes (2006), os resultados insatisfatórios obtidos pela maioria dos alunos surdos no processo escolar decorrem da falta de uma metodologia de ensino adequada. Podemos acrescentar a este panorama questões relacionadas à adequação e à produção de materiais que estabeleçam a transposição didática de conteúdos relacionados à modalidade escrita da Língua Portuguesa. Nota-se, no entanto, que a oferta de tais materiais dirigidos à comunidade surda é escassa ou, quando existente, não atende ao desenvolvimento das interfaces de leitura e escrita do Português desse alunado (LEITE \& CARDOSO, 2009).

É a partir dessas considerações que podemos falar de uma experiência acadêmica realizada, desde 2009, no Instituto de Letras da Universidade do Estado do Rio de Janeiro (UERJ). Trata-se de uma disciplina obrigatória oferecida no curso de Letras da referida instituição, cujo nome é "Estágio: Planejamento de materiais no ensino de português como L2 para a comunidade surda".

\section{SOBRE A DISCIPLINA}

Segundo Perse (2011), das cinco universidades públicas do Rio de Janeiro que foram foco de suas análises, somente a UERJ oferece o curso que tem como ênfase o ensino de língua portuguesa como segunda língua para surdos. Entendemos que a colocação de Perse (2011) sugere que esse tipo de ensino é uma prática que ainda precisa ser implementada em outros espaços de formação de professores de línguas. Assim sendo, optou-se por divulgar, por meio de relato, a experiência acadêmica realizada na referida instituição.

A disciplina "Estágio: Planejamento de materiais no ensino de português como L2 (PL2) para a comunidade surda", que compõe o quadro das práticas curriculares do curso de Letras da UERJ, visa a abordar questões ligadas ao ensino de PL2 destinado à comunidade surda e propõe estabelecer metodologias de ensino e produção de materiais didáticos que possam auxiliar os futuros docentes a desenvolver o letramento ${ }^{1}$ de alunos surdos em Língua Portuguesa. Seu objetivo geral é instrumentalizar o futuro professor

\footnotetext{
${ }^{1}$ Enfatiza-se o processo de letramento visto que as atividades de ler e escrever são oriundas de diversas esferas sociais e implicam na exposição do aluno aos mais variados gêneros textuais que circulam na sociedade.
} 
dessa língua a lidar com as singularidades linguísticas da comunidade surda pelo viés da transposição didática, com a análise, a avaliação e a elaboração de propostas didáticas direcionadas a esses alunos. Em suma, procura-se suscitar a compreensão de como a experiência visual, amplamente defendida pelas pesquisas na área de educação e surdez, pode corroborar com o processo de ensino-aprendizagem da Língua Portuguesa escrita.

Tendo em vista o panorama da educação de surdos numa perspectiva bilíngue, os objetivos específicos da disciplina são: a) divulgar a LIBRAS, a cultura surda e a especificidade do processo de leitura e escrita em PL2 por alunos surdos; b) definir critérios para análise e avaliação crítica de materiais didáticos de língua portuguesa para alunos surdos; c) adaptar e elaborar materiais para contextos de ensino de português como segunda língua para esses alunos; d) desenvolver práticas pedagógicas que visem à criação de escopo teórico-metodológico acerca de atividades dirigidas aos aprendizes surdos, em especial, aquelas que abordem os diversos gêneros textuais circulantes na sociedade; e) colaborar com a formação docente em língua portuguesa, no tocante ao desenvolvimento de novas estratégias de ensino para surdos.

O programa delineado busca suscitar a construção de conhecimento sobre novas metodologias e estratégias didáticas. Em consonância com seus objetivos, o escopo metodológico da disciplina deve englobar três eixos temáticos, cujas especificidades se baseiam em propor a criação de recursos e metodologias de caráter inovador e experimental visando às necessidades linguísticas da comunidade surda. São eles: 1) divulgação da LIBRAS e da cultura surda; 2) compreensão das especificidades da produção textual em PL2; 3) análise, avaliação, adaptação e elaboração de MD para o ensino de PL2 para alunos surdos.

O primeiro eixo, voltado à difusão da Língua de Sinais e suas especificidades, propõe oferecer ao graduando informações essenciais sobre a língua de sinais, os aspectos sociais da surdez e o aluno surdo. O segundo eixo destina-se à discussão do desenvolvimento da leitura e da escrita em PL2 por alunos surdos. Pretende-se, a partir de análise das produções, verificar o papel da LIBRAS no processo de aquisição da modalidade escrita da PL2. O terceiro eixo visa ao conhecimento e à reflexão acerca de metodologias e materiais já desenvolvidos com este grupo discente, bem como promover a descrição do material didático (MD) para identificar a metodologia e os princípios organizacionais utilizados. O eixo também contempla a adaptação e a elaboração de MD à comunidade surda, propondo um trabalho baseado no letramento e no uso de diversos recursos textuais e imagéticos. Deve-se sublinhar que para ensinar 
uma L2 o professor deve conhecer a L1 de seu aluno, assim como questões relacionadas ao bilinguismo, ao multiculturalismo, às imagens construídas para cada língua envolvida no processo de ensino-aprendizagem.

\section{Outra realidade, outra forma de compreender o mundo}

As atividades desenvolvidas no primeiro eixo buscam familiarizar os graduandos com o "mundo dos surdos", sua língua e sua cultura. São apresentados documentários, vídeos com histórias em LIBRAS, aspectos da vida social e esportiva, artes visuais, movimentos sociais dos surdos. Além dessas atividades, são realizadas oficinas de sensibilização para a questão da surdez entendida como uma diferença.

Distintas das línguas orais, as línguas de sinais são de modalidade espaço-visual. Os sinais e expressões compõem as categorias gramaticais e funcionais da Libras. Afirmar isso é dizer que, ao contrário do que muitos pensam, os sinais e as expressões feitos pelos surdos não são simples gestos e nem mímica. A LIBRAS não é uma adaptação das línguas orais, não é um "Português sinalizado", é, pois, uma língua ilimitada; ou seja, possui gramática própria, variações, diversidade, entre outros aspectos.

A língua de sinais é uma das maneiras dos surdos estarem no mundo e significálo. Eles apreendem o mundo com os olhos e, por isso, sua cultura está baseada na visão. Trata-se, portanto, de um modus vivendi, mas isso não quer dizer que não compartilhem com os ouvintes a cultura nacional ou mesmo a universal; muito pelo contrário, os sujeitos surdos podem ser considerados multiculturais (SALLES et al, 2004).

\section{O que fazer com o texto do aluno surdo?}

No segundo eixo, busca-se aplicar a base teórica tanto da área de aquisição de L2, como da Linguística Aplicada. Sem dúvida a literatura das duas áreas pode auxiliar na indicação de caminhos para o ensino-aprendizagem de leitura e de escrita de PL2. No que diz respeito à aquisição de segunda língua, o aluno surdo - como qualquer outro aluno - não a aprende mecanicamente e sim utiliza estratégias de simplificação, hipergeneralização e transferência da sua L1. Essa articulação entre as duas línguas é chamada de interlíngua (SELINKER, 1972). Esse esquema, construído no aprendizado de uma segunda língua, não é nem a L1 nem a L2, mas um conjunto de regras 
temporárias que são usadas sistematicamente até que os dados colhidos do meio ou indiquem que a hipótese está errada e que o caminho é outro ou reforcem a hipótese, solidificando a regra.

Há de se considerar, portanto, que o ensino da modalidade escrita da PL2 para alunos surdos deva contemplar o desenvolvimento do letramento com centralidade no processo da interlíngua. Sobrepõe-se a contextualização visual do texto, cuja importância permitirá ao aluno surdo a elaboração de hipóteses sobre a leitura, como a escrita de seu próprio texto. A noção de interlíngua, segundo Dechandt (2006), torna-se proveitosa para a análise das produções escritas de alunos surdos, visto que "há marcas de instabilidade que refletem uma competência transicional e demonstram que o aprendiz não aprende uma língua mecanicamente, mas que se utiliza de estratégias de transferência da L1 [...]” (DECHANDT, 2006, p. 292).

Face às questões apresentadas, é possível, através da análise da produção textual $^{2}$ de alunos surdos, relacionar o conhecimento teórico ao prático. Nessas atividades, os graduandos em Letras têm a oportunidade de reconhecer qual é o papel da LIBRAS na produção textual de alunos surdos e propor critérios para sua análise e avaliação dos textos.

\section{Avaliar, adaptar e elaborar: uma mesma competência?}

Pode-se dizer que o programa da disciplina concentra-se na análise, adaptação e elaboração de materiais didáticos de ensino de PL2. A principal proposta do terceiro eixo é avaliar materiais e discutir sua importância no processo de ensino aprendizagem de PL2 para alunos surdos. Tais discussões, no entanto, não devem se restringir ao livro didático, embora este também seja um instrumento utilizado na prática de ensino de PL2. Além dos livros didáticos (vistos, em geral, como material didático por excelência), CD-roms, filmes, músicas, textos autênticos, exercícios elaborados pelo docente também devem ser considerados materiais didáticos. Caberá ao futuro professor identificar tais modalidades de materiais e empregá-las de acordo com os objetivos, características e necessidades de cada situação de ensino.

Em relação à análise de $\mathrm{MD}$, assume-se uma postura de descrever suas características e seus objetivos; em outros termos, promove a descrição do MD de forma

\footnotetext{
${ }^{2}$ As produções textuais são retiradas de livros e de pesquisas realizadas na área, sobretudo, de teses e dissertações.
} 
a identificar a metodologia e os princípios organizacionais utilizados. Já a avaliação pode ser entendida como o julgamento do MD para alguma finalidade, em geral, adoção com base em critérios, necessidades, características e objetivos da situação de ensinoaprendizagem. Em suma, o objetivo da avaliação é conferir a adequação do material ao contexto específico de ensino de uma língua e às suas características.

Como inexistem critérios estritamente definidos para a análise e avaliação de materiais de português para alunos surdos, consideramos, em um primeiro momento, a proposta de Tomlinson \& Masuhara (2005) que identifica existência de três tipos de avaliação, quais sejam: a) avaliação de pré-utilização; b) avaliação durante a utilização; c) avaliação de pós-utilização. Já para Holden \& Rogers (2001), a análise de materiais deve estar pautada em critérios como: interesse e relevância para o aluno; facilidade de uso; nível do idioma; durabilidade do material, entre outros.

Pelo caráter da disciplina, focamos na avaliação de pré-utilização, destacando, não somente os critérios elencados por Holden \& Rogers (2001), mas também critérios que levem em conta o modus vivendi surdo. Dessa forma, é importante construir com os graduandos critérios de avaliação de materiais endereçados a alunos surdos, dos quais citamos alguns exemplos: a) referência à língua de sinais; b) análise contrastiva das duas línguas; c) inserção de elementos visuais.

A competência para avaliar esses e outros MD, como destaca Vilaça (2009), contribui para adaptar e elaborar novos materiais. Seguimos a proposta de Villaça (2009), na qual há alguns movimentos possíveis na adaptação de materiais, a saber: 1) adição de atividades, tarefas, materiais extras; 2) apagamento de parte do material didático; 3 ) modificação parcial de tarefas e atividades; 4) simplificação de objetivos e os procedimentos de uma tarefa ou atividade; 5) reordenamento das atividades.

Considerando esses movimentos, selecionamos dois tipos de materiais que podem ser adaptados: a) materiais para o ensino de LP como língua materna (LM); b) materiais para o ensino de LP como língua estrangeira (LE), dando maior ênfase nos últimos. As adaptações feitas (transcrição de diálogos orais gravados em Cd-rom e sua tradução em Libras, por exemplo) já demonstram uma faceta da produção de materiais. Por tal condição, a adaptação deve ser considerada como uma forma de contribuir para a capacidade de elaborar MD, competência que deve fazer parte da formação de qualquer professor de línguas. Em outros termos, a adaptação de MD já é, em certa medida, uma forma de produzir materiais. 
Especificamente sobre a elaboração de materiais, Leffa (2008) afirma que se deva mostrar compatibilidade entre o contexto de ensino-aprendizagem, os objetivos e os recursos de aprendizagem. E também deve envolver, sobretudo, a análise das necessidades dos alunos. Somente a partir delas que podem ser definidos os objetivos que direcionarão o desenvolvimento do material e quais conteúdos serão selecionados (LEFFA, 2009). Essa é uma questão importantíssima na tarefa de elaboração de materiais para o alunado surdo.

Vilaça (2009), por sua vez, aponta duas possibilidades para a elaboração de materiais. A primeira é baseada nas experiências anteriores do professor (elaboração por intuição). A segunda é a elaboração de materiais partindo de teorias e pesquisas na área do ensino de línguas. Segundo o autor, "pesquisas teóricas de diversos autores são levadas em consideração, em menor ou maior proporção, para a elaboração de materiais" (VILAÇA, 2009, p. 86). No caso da disciplina, como em geral os graduandos não têm experiência no ensino de PL2 para surdos, a elaboração se converge para segunda possibilidade. As pesquisas acadêmicas e as atividades de sensibilização, desenvolvidas no primeiro eixo, fornecem as bases para subsidiar a elaboração de materiais.

Destaca-se que os materiais elaborados devam contar com recursos visuais, essenciais nesse contexto de ensino. Uma pedagogia visual no ensino de PL2 para alunos surdos deve seguir um funcionamento específico. Não se trata de mostrar imagens e aplicar atividades nos mesmos moldes do ensino dessa língua para ouvintes. As atividades de leitura de imagens, por meio da língua de sinais $^{3}$, devem suscitar o conhecimento prévio sobre a temática, promover o conhecimento de mundo do aluno, ampliar o vocabulário do aluno em sua L1 e auxiliar na realização de inferências. Em seguida, há apresentação do texto escrito em língua portuguesa. A partir desses pontos, sugerimos o trabalho com a leitura do texto (passando pelas etapas de pré-leitura, leitura e pós-leitura) e por fim, a escrita de textos em Língua Portuguesa.

\section{PARA FINALIZAR}

A formação docente deve ser um espaço fomentador de discussões sobre os processos de ensino-aprendizagem, na busca de metodologias que satisfaçam as

\footnotetext{
${ }^{3}$ Destacamos a necessidade premente de um bom nível de proficiência em Libras, seja do professor seja do intérprete.
} 
necessidades do alunado. Considerando a formação em Língua Portuguesa, sabe-se que esta, muitas vezes, não contempla uma preparação ao futuro docente acerca dos trabalhos com a comunidade surda e do estabelecimento de uma prática pedagógica que atenda as particularidades linguísticas do sujeito surdo. Dessa maneira, busca-se, com essa disciplina, dar ao futuro docente bases para uma prática pedagógica em PL2 que contemple as questões do letramento. É indispensável que vários gêneros textuais sejam ensinados na escola básica - tanto para alunos ouvintes quanto para surdos. Em relação aos últimos, deve-se também considerar, na transposição didática dos gêneros, a necessidade de formular sequências didáticas com muitos recursos visuais - que estimulem e incorporem a experiência visual e a cultura surda.

A disciplina busca tanto suscitar a produção prática e a reflexão teórica necessárias à elaboração de materiais e de sequências didáticas que visem às especificidades do processo de ensino-aprendizagem de alunos surdos quanto reafirmar que as ferramentas pedagógicas voltadas para esse alunado pressupõem categorias distintas daqueles endereçadas a alunos ouvintes. Defendemos que para o ensino bilíngue se tornar uma opção educacional real, é necessário investimento na formação do professor, no ensino de LIBRAS e, principalmente, na produção de materiais voltados para esse contexto pedagógico.

\section{REFERÊNCIAS}

BRASIL. Lei $n^{o} 10.436$, de 24 de abril de 2002. Dispõe sobre a Língua Brasileira de Sinais. Diário Oficial [da República Federativa do Brasil], Brasília, DF, n. 79, p. 23, 25 abril 2002.

Dechandt, S. B. (2006). A apropriação da escrita por crianças surdas. In: Quadros, R. M.(org.). Estudos Surdos I. 284-322. Petrópolis, RJ: Arara Azul.

Fernandes, S. (2007). Avaliação em língua portuguesa para alunos surdos: algumas considerações. Curitiba: Secretaria de Estado da Educação.

Holden, S. \& Rogers, M. (2001). O ensino da língua inglesa. São Paulo: SBS Editora.

Leffa, V. (2008). Como produzir materiais para o ensino de línguas? In: Leffa, Vilson. (Org.). Produção de materiais de ensino: teoria e prática. 2ed. 15-41. Pelotas: EDUCAT. 
Leite, J. G. \& Cardoso, C. J. (2009). Inclusão Escolar de Surdos: Uma análise de livros de alfabetização. In: Anais do IX Congresso Nacional de Educação - EDUCERE. 34343446. Curitiba: Champagnat.

Perse, E. L. (2011). Ementas de LIBRAS nos espaços acadêmicos: que profissionais para qual inclusão? Dissertação de Mestrado inédita, Universidade do Estado do Rio de Janeiro.

Salles, H. M. M. L. et al. (2004). Ensino de língua portuguesa para surdos: caminhos para a prática pedagógica. v1. Brasília: MEC, SEESP.

Selinker, L. (1972). Interlanguage. International Review of Applied Linguistics, 10, (3), 209-31.

Tomlinson, B. \& Masuhara, H. E. (2005). Elaboração de materiais para cursos de idiomas. São Paulo: SBS Editora.

Vilaça, M. L. C. (2009). Estratégias de aprendizagem e materiais didáticos de língua estrangeira: elaboração, integração, ensino e percepção. Tese de Doutorado inédita, Universidade Federal Fluminense.

\section{A AUTORA}

Angela Corrêa Ferreira Baalbaki é mestre em Letras pela Universidade do Estado do Rio de Janeiro (UERJ) e doutora em Letras pela Universidade Federal Fluminense (UFF). É professora do Departamento de Estudos da Linguagem do Instituto de Letras UERJ. Em 2011, foi professora temporária do Departamento de Educação Superior (DESU) do Instituto Nacional de Educação de Surdos (INES). Integra os grupos de pesquisa: Discurso, historicidade e subjetividade: inconsciente e ideologia; Práticas de Linguagem e Subjetividade - PraLinS e Estudos Histórico-Sociais da Ciência (MAST). Desenvolve pesquisas com ênfase nos seguintes temas: formação de professores de línguas, processo de gramatização de línguas, ensino de português como segunda língua para surdos, discurso de divulgação científica.

E-mail: angelabaalbaki@hotmail.com 